\title{
A crítica como missão: formação e modernização na obra de Sérgio Buarque de Holanda
}

\author{
Henrique Pinheiro Costa Gaio*
}

Nicodemo, Thiago Lima. Alegoria moderna: crítica literária e história da literatura na obra de Sérgio Buarque de Holanda. São Paulo: FAP-Unifesp, 2014.

Sérgio Buarque de Holanda (1902-1982) tem uma obra volumosa e que transitou entre a crítica literária, o ensaísmo e a escrita histórica monográfica. Talvez não seja equivocado dizer que sua trajetória intelectual, sobretudo entre os anos 1920 e 1950, pode funcionar como uma espécie de metonímia do processo de profissionalização do historiador ou de autonomização do campo, tendo como referência importante a consolidação de instituições universitárias no Brasil. Sua obra mostra-se encorajadora de imensa fortuna crítica: variadas abordagens demonstram não somente a juventude perene de um pensador clássico como também ilumina certas nuances da reflexão buarquiana. É justamente neste contexto de ampliação e sedimentaçáo da fortuna crítica do autor que tanto serve como estorvo para leituras ingênuas como também instiga novos caminhos de pesquisa - que Alegoria moderna: crítica literária e história da literatura na obra de Sérgio Buarque de Holanda (2014), de Thiago Lima Nicodemo, deve ser inserido.

A trajetória da pesquisa de Thiago Nicodemo parece traçar um movimento contrário ao do processo de profissionalizaçáo do historiador, uma espécie de leitura a contrapelo ou teleologia às avessas. Nicodemo, em seu livro anterior, fruto de sua dissertação de mestrado, Urdidura do vivido: Visão do paraíso e a obra de Sérgio Buarque de Holanda nos anos de 1950 (2008), lidou com um momento basilar no trabalho de Sérgio Buarque: o processo de especialização que culmina com a feitura de Visáo do paraíso (1958) e sua inserção universitária. Em sua nova publicação, Nicodemo recua cronologicamente com o intuito de perscrutar o processo de formaçáo do historiador acadêmico, abarcando desde a década de 1920 até a de 1950, ou seja, a passagem do jovem crítico modernista, atento ao debate dos dilemas da modernização nacional, para o historiador maduro que opta por cortes mais circunscritos em detrimento de generalizaçốes e que, sobretudo, mescla com peculiar maestria erudição e imaginação. $\mathrm{O}$ arco 
cronológico abarcado pela pesquisa permite uma compreensão abrangente da formação do intelectual; por meio do cruzamento entre crítico literário, ensaísta e historiador, é possível mapear interesses recorrentes e constantemente burilados. Tal esforço de cruzamento já demonstra a relevância da pesquisa que temos em máos.

Ao retornar para a década de 1920, Thiago Nicodemo aponta para os interesses compartilhados com aquela geração e a influência duradoura de temas tipicamente modernistas ao longo da vida intelectual de Sérgio Buarque de Holanda. Para além da definição estanque do jovem modernista ou do historiador maduro, almeja demonstrar certa continuidade, ou seja, a importância do resgate de sua produção de crítica literária como forma de compreender sua formação intelectual e o desenvolvimento intermitente de temas fulcrais na sua reflexão. Nicodemo realiza um bem-sucedido esforço de lastrear o caráter de missão que orienta a trajetória de Sérgio Buarque de Holanda, pois ao definir precursores e ao reconhecer a manutenção de assuntos do jovem modernista na pena do historiador maduro demonstra a unidade do pensamento e certo sentido da escrita.

Sérgio Buarque molda sua crítica por meio de uma metodologia fugidia e diversificada, todavia, esforça-se para estabelecer um diálogo entre obra e tradição, autor e ambiente de escrita. Segundo Antonio Candido, para se ter dimensão da fortuna da contribuição do jovem crítico, às vezes é preciso compreender que ela se articula "com todo um ciclo da civilização a que pertence, como no caso da extraordinária análise de Cláu- dio Manuel da Costa”, quando o crítico, de acordo com Candido, "circula no tempo, vai até Petrarca, vem até Lope de Vega, vai até Dante Alighieri, vem a Metastasio, volta para Cláudio Manuel da Costa, a constelação vai se formando e você sente que para explicar aquele texto curto de catorze versos ele mobiliza a civilização do Ocidente."1 Tal comentário mostra-se importante para indicar não só a conhecida erudição do crítico, mas também a dimensão histórica que se revela no diálogo da obra literária com uma tradição ocidental.

Nicodemo, evitando o risco e o reducionismo da influência, explora o impacto da viagem de Sérgio Buarque aos Estados Unidos, em 1941, momento em que entrou em contato com os pressupostos teóricos do new criticism, que reivindicava a autonomia do texto literário em relação à biografia do autor e o ambiente de sua produção. A técnica do close reading, no entanto, não provocou no crítico o descarte da historicização da estrutura linguística e estética. A experiência norte-americana, mesmo com seu valor na institucionalização disciplinar, trazia como corolário um formalismo radical que soava como conservadorismo. Além disso, o "senso das coalescências", indicado por Candido na crítica literária de Sérgio Buarque, apontava para o jogo de semelhanças e diferenças, rupturas e permanências. Portan-

${ }^{1}$ CANDIDO, Antonio. Apud PRADO, Antonio Arnoni. Introdução. In: HOLANDA, Sérgio Buarque de. $O$ espirito e a letra: estudos e crítica literária. São Paulo: Companhia das Letras, 1996, p. 32. Ver também: CANDIDO, Antonio. Inéditos sobre literatura colonial. In: Sérgio Buarque de Holanda: 3. Colóquio Uerj — Rio de Janeiro: Imago, 1992. 
to, o crítico, ao temporalizar a experiência estética, recusava deliberadamente fazer da historiografia literária um mero catálogo de escolas. Desse modo, a historicidade literária, segundo a crítica buarquiana, implica não ignorar que a obra de ficção seria fruto de certa inserção no tempo, condicionada por determinado horizonte histórico, donde o autor não pode mais ser visto como um gênio romântico que prescinde do mundo para criar. Assim, o que parece estar em jogo são as condições de possibilidade de criação literária ou a "pesquisa da constituição do texto". Dito em outras palavras, sem denegar a autonomia da linguagem da ficção, o crítico busca combinar sua análise aos estratos históricos que possibilitam a feitura do artefato literário.

A chave de leitura de Candido, também seguida por Antonio Arnoni Prado, parece funcionar como um fio condutor de Alegoria moderna. Não somente porque existe um deliberado esforço de continuação de certa tradição interpretativa, algo demarcado claramente ao longo do trabalho, mas também porque a missão modernista parece conferir sentido ao processo de profissionalização das letras nacionais. Seguindo os passos de Mário de Andrade, inclusive o substituindo no Diário de Notícias em 1941, Sérgio Buarque, desde sua militância modernista, assume o compromisso da especialização e da superação de uma cultura de superfície, pautada por bacharéis e medalhóes, críticos impressionistas e historiadores diletantes. Tais personagens funcionariam como arautos de uma palavra vazia, palavra feito ornamento, ou ainda, como um passado que ainda se faz presente, algo que depóe contra o esforço de modernização das letras nacionais. Thiago Nicodemo, ao alargar a crítica literária de Sérgio Buarque num horizonte mais amplo de exortação de mudanças na intelectualidade brasileira, identifica sua dimensão cultural e sua inserção no processo de autonomização do campo intelectual, tal como pensado por Pierre Bourdieu.

Se a costura do trabalho de Thiago Nicodemo é o reconhecimento de certa missão crítica de superação de traços coloniais, conferindo unidade à reflexão, faz-se necessário dizer que isso não implica carência de contradiçôes ou o descarte de rasuras significativas na obra de Sérgio Buarque. Os planos de historicidade que se manifestam em modificaçōes nas três primeiras ediçôes de Raizes do Brasil, as intersecções entre Visão do paraíso (1958) e Capitulos de literatura colonial (1991), assim como a recorrência dos temas, revelam a presença de diversas temporalidades na orientação e reorientação da escrita buarquiana. ${ }^{2}$ Como em um palimpsesto, onde horizontes históricos se cruzam na constante atividade de reescrita que não apaga de todo o passado, a escrita ficcional e o próprio ato crítico são marcados pela passagem do tempo e por uma consciência histórica que desempenha um papel estruturante. A abordagem hermenêutica mobilizada por Nicodemo, valendo-se de autores como Hans-Georg Gadamer e Jörn Rüsen, numa espécie de duplicação da abordagem buarquiana, permite compreender a dimensão

\footnotetext{
${ }^{2}$ NICODEMO, Thiago Lima. Planos de historicidade. História da Historiografia, Ouro Preto, n. 14, p. 44-61, abr. 2014. Disponível em: <www.historiadahistoriografia.com.br>. Acesso em: 4 ago. 2016.
} 
estética no interior de estruturas históricas, sem, contudo, subsumir uma na outra. Desse modo, segundo alerta Thiago Nicodemo, "não é possível afirmar que Sérgio Buarque de Holanda possuía uma 'concepção' de crítica literária, já que sua ideia era justamente buscar um 'ajuste' entre o horizonte criativo e o horizonte crítico". ${ }^{3}$ Além do reconhecimento do caráter movediço da reflexão, o sentido de missão de Sérgio Buarque parece ter sido captado em seu momento de engendramento, evitando-se certa teleologia que descrevesse sem tensões a transição do crítico diletante para o historiador profissional.

Thiago Nicodemo movimenta-se entre texto e contexto esquivando-se das dicotomias e do equívoco das influências reguladoras. Tal cuidado teórico fica patente ao demonstrar o impacto da experiência italiana na feitura do estudo inacabado que dá origem a Capitulos de literatura colonial - título concebido por Antonio Candido aos rascunhos encontrados postumamente e publicados em 1991. Detalhando a vivência italiana por meio de ampla documentação (cartas, documentos do Itamaraty, ementas de disciplina etc.), Nicodemo, seguindo a sugestão de Candido sobre uma "fase italiana” (1952-1954), descreve as condiçôes que possibilitam a redação de Capitulos de literatura colonial e Visão do paraíso, ou seja, articula um momento fundamental da trajetória tanto do crítico quanto do historiador. ${ }^{4} \mathrm{~A}$

\footnotetext{
${ }^{3}$ NICODEMO, Thiago Lima. Alegoria moderna: crítica literária e história da literatura na obra de Sérgio Buarque de Holanda. São Paulo: FAP-Unifesp, 2014, p. 125.

${ }^{4}$ CANDIDO, Antonio. Introdução. In: HOLANDA, Sérgio Buarque de. Capitulos de literatura colo-
}

influência de pensadores como Mario Praz e Benedetto Croce, assim como a familiaridade com autores italianos do Renascimento, Barroco e Arcadismo, permitiu a ampliação do aparato erudito do crítico e o distanciamento de um nacionalismo literário típico do século XIX — mas que se estendeu, não sem alteraçóes, até a década de 1950 como "nacionalismo estratégico", na definição de Antonio Candido.

Admitindo-se a concomitância da pesquisa e escrita de Capitulos de literatura colonial e Visão do paraíso na década de 1950, mostra-se relevante o distanciamento de uma historiografia literária que se amparava na reconstituição de origens e no esforço de identificação de nativismos pretéritos, buscando retrospectivamente eventos que permitissem elaborar uma narrativa redentora da formação, numa espécie de anunciação da presença. Evitando a orientação interessada do nacionalismo que pautava a historiografia literária tradicional, Sérgio Buarque procurou a articulação do passado literário nacional por meio dos topoi. Nesse sentido, o trabalho de Ernest Robert Curtius, Literatura europeia e Idade Média latina (1948), torna-se central para compreender o papel que as permanências literárias que atravessam fronteiras e remetem a uma herança retórica antiga adquirem na reflexão buarquiana da década de 1950.

A tópica enquanto "celeiro de provisóes" literárias, tal como anunciada por Curtius, foi fundamental na feitura de Visão do $p a-$ raíso. ${ }^{5}$ Os motivos edênicos que impulsio- 
nam o ideal aventureiro dos descobrimentos e organizam os primeiros contatos com o Novo Mundo não somente criavam uma tensão entre experiência e fantasia, mas também imputavam ao estilo condicionamentos históricos, podendo inclusive expor novas disposiçóes subjetivas. Nicodemo, que, seguindo a sugestão de Luiz Costa Lima, estudou com densidade o uso da tópica na costura de Visão do paraíso, estendeu sua análise para Capitulos de literatura colonial. Esse movimento mostra-se extremamente profícuo para a compreensão do esboço de historiografia literária de Sérgio Buarque.

Segundo Nicodemo, o autor aponta para uma "longa permanência da épica como padrão figurativo da literatura na América portuguesa", o que significou o afastamento da influência romântica na avaliação do passado literário colonial. Desse modo, o gênero tornou-se, para o crítico e historiador, "ponto de partida para compreender os textos como parte de um tecido social e, por isso, em constante interação com um público dotado de horizonte específico". ${ }^{6}$ Dito de outra forma, como consequência desse ponto de partida, a demonstração da extensão do gênero épico, que perpassa o século XVII e estende-se até o XIX, indica a força da

Idade Média latina. Rio de Janeiro: Instituto Nacional do Livro, 1957. Ver também: LIMA, Luiz Costa. Sérgio Buarque de Holanda: Visão do paraíso. Revista USP, São Paulo, n. 53, p. 42-53, mar./maio 2002. Disponível em: <http://www.revistas.usp.br>. Acesso em: 4 ag. 2016; NICODEMO, Thiago Lima. Urdidura do vivido. Visão do paraíso e a obra de Sérgio Buarque de Holanda nos anos de 1950. São Paulo: Editora da Universidade de São Paulo, 2008.

${ }^{6}$ NICODEMO, Thiago Lima, Alegoria moderna: crítica literária e história da literatura na obra de Sérgio Buarque de Holanda, op. cit., p. 216. convenção em detrimento de uma originalidade de traço romântico, donde a emulação e a engenhosidade possuem uma ocorrência técnica. Assim, segundo a leitura proposta por Nicodemo, "a literatura na América portuguesa busca conferir dignidade épica a temas figurados no território ultramarino", ou seja, a história da literatura colonial parece ser o relato da gradativa adaptação de códigos literários europeus ao ambiente americano. $\mathrm{O}$ intuito de inserir a América no quadro imagético europeu faz com que Capitulos de literatura colonial tenha como estrutura narrativa a formação da tópica do "mito americano" ou "tópica do sentimento nacional". Portanto, figura como uma espécie de continuação de Visáo do paraíso.

No âmbito de uma história cultural, o que emerge do uso da tópica é uma consciência histórica que se molda por meio da tensão entre um modelo figurativo associado ao corpo místico, fundamentação do Estado Absoluto, e o gosto arcádico que se vincula ao modelo figurativo da modernidade. Nesse jogo entre o antigo e o novo, compreender a permanência de barroquismos, de uma hiperbólica e retorcida linguagem, significa ater-se à dificuldade de sedimentação da clareza e sobriedade árcade, significa problematizar os estorvos impostos à modernização da cultura, investir no descompasso entre os influxos do iluminismo e o desenvolvimento do "gosto árcade". Segundo Nicodemo, investir em tal tensão pressupóe que "a cultura cumpre, enfim, um papel fundamental e oferece para Sérgio Buarque de Holanda a chave da compreensão do processo histórico

\footnotetext{
${ }^{7}$ Ibidem, p. 221.
} 
de formação (...)". 8

O descompasso ou o impasse da modernização remete à questão do Barroco. Em Capitulos de literatura colonial, o Barroco aparece não somente como parte das demandas crítico-literárias da década de 1950 , condicionada pelo resgate de procedimentos poéticos herméticos, mas como possibilidade de se pensar a formação nacional — tema caro aos modernistas. Nicodemo demonstra como a preocupação com o papel do "longo barroco" na colônia não aparece de maneira fortuita na obra de Sérgio Buarque. Este, além de anunciar na terceira edição de Raízes do Brasil, de 1956, A Era do Barroco no Brasil (Cultura e vida espiritual nos séculos XVII e XVIII) como obra em preparo e indicando a realização de três volumes - trabalho nunca realizado - , parecia querer articular uma mentalidade barroca com seu diagnóstico dos problemas da formação nacional.

Assim, o que está em jogo para Nicodemo, em sua proposta de relacionar a história literária buarquiana com a formação nacional, não é somente o caráter convencional da literatura colonial que se pautava em preceptivas retórico-poéticas rígidas, mas a dimensão histórica do processo de acomodação dessas preceptivas, justamente a possibilidade de amolecimento ou de misturas de gêneros. A tradição ibérica, desse modo, pressupóe a força da figuração barroca que se prolonga até o início do século XIX, marcando a manutenção de uma linguagem alambicada e de uma mentalidade formatada pela aversão às hierarquias e à hegemonia dos laços familiares e patriarcais. Nesse ponto, o tema central de Raizes do Brasil, a preocupação com a superação do passado ibérico que teima em impor-se diante da vontade de modernização, parece prolongar-se na reflexão buarquiana.

Fruto de tese de doutoramento, Alegoria moderna tem como mérito investir, com resultados profícuos, em veredas sugeridas pela fortuna crítica do autor analisado, mas ainda não percorridas. Thiago Nicodemo acrescenta mais um traço firme no quadro interpretativo-analítico da obra buarquiana, como também de sua própria trajetória acadêmica, que vem se caracterizando por pesquisa consistente e esforço contínuo de compreensão da escrita de Sérgio Buarque de Holanda.

\footnotetext{
${ }^{8}$ Ibidem, p. 236.
} 